\title{
Ambulatory Blood Pressure and Arterial Stiffness in Obese Children and Adolescents
}

\author{
Duicu Carmen ${ }^{1 *}$, Mărginean Cristina Oana ${ }^{1}$, Pitea Ana Maria1 ${ }^{1}$, Melit Lorena Elena² \\ 1 University of Medicine and Pharmacy Tirgu Mureș, Romania, $1^{\text {st }}$ Department of Pediatrics \\ 2 Emergency Clinical County Hospital of Tirgu Mureș, Romania, Pediatrics Clinic 1
}

The aim of the present study was to investigate differences regarding 24-hour blood pressure and arterial stiffness in a cohort of office normotensive obese and non-obese children and adolescents, and to evaluate correlations of these parameters with some anthropometric indices. We retrospectively evaluated ABPM records in 71 children (42 boys); 31 obese compared with 40 normal-weight children. Results: Mean 24-hour, day-time and night-time SBP was significantly higher in the obese group than in the control group ( $p<0.01$ during the entire period). Significantly higher AASI values were found in obese children compared to controls (0.45 vs. $0.41, p<0.05)$, the difference being more obvious for day-time AASI $(p<0.001)$. Conclusions: This research confirms that SBP and AASI are increased in obese children. AASI is a useful index of arterial stiffness that can be easily measured under ambulatory circumstances in children.

Keywords: ambulatory blood pressure, obese, children, arterial stiffness

Received: 13 August 2015 / Accepted: 03 September 2015

\section{Background}

Obesity became an important public health problem for many countries including our country, where the increasing prevalence in the last years is alarming. A study performed in 2009 in central Romania found that obesity incidence among school-aged children was $8.29 \%$ and overweightwas $12.84 \%$, with a higher incidence in boys [1]. In western Romania a high prevalence of overweight (18.2\%) and obesity in children (7.2\%) have been confirmed recently [2], while in north-eastern Romania [3] higher prevalence of nutritional disorders were proved (overweight $24.6 \%$ in boys and $22.7 \%$ in girls; obesity in $7.8 \%$ of boys and $6.4 \%$ of girls).

The increasing associated morbidity of obesity in children and adolescents has resulted in a significant disease problem (high blood pressure, dyslipidemia, type 2 diabetes, bone and joints involvement, pulmonary disease, psychological problems, etc.) $[4,5]$.

It is well-known that obesity, high blood pressure (BP), type 1 diabetes mellitus and arterial stiffness are risk factors for cardiovascular disease $[6,7,8]$. A strong relationship exists between obesity and elevated BP in both children and adults. Obesity and elevated BP in childhood follows into adult life expanding the risk of cardiovascular disease in adulthood [4,9].

Ambulatory blood pressure monitoring (ABPM) represents a valuable diagnostic tool to assess $\mathrm{BP}$ in children [10]. ABPM in children and adolescents was used according the guidance of American Heart Association [11].

The usefulness of ABPM to classify BP is demonstrated by several studies $[10,11]$.

The reference values for ambulatory blood pressure measurementsused in this study, are those provided by the German Working Group on Pediatric [12].

High blood pressure, obesity, diabetes mellitus and dyslipidemia, well known risk factors for cardiovascular disease, are associated with increased arterial stiffness (loss of elasticity) $[13,14]$. Ambulatory blood pressure monitoring (ABPM) may be used to calculate in a simple manner the pulse pressure (PP) and ambulatory arterial stiffness index (AASI). These last two parameters have been suggested as markers of arterial stiffness and predictors of cardiovascular mortality [6].

In the last yearsa new index of arterial stiffness: the ambulatory arterial stiffness index (AASI) was proposed [8,15-17]. It can be easily measured in ambulatory conditions and computed through a simple formula. AASI is defined as it follows: 1 minus the regression drop of DBP plotted against SBP achieved from every subject's 24-h blood pressure recordings $[8,16]$.

Dipping is defined as the percentage slope from mean daytime to mean nighttime levels [14]. Non-dipping is a common occurrence among obese children and adolescents [18].

\section{Material and methods:}

The children and their parents were informed about the research protocol prior to be included in the study. All guardians signed an informed consent that was approved by the local ethics committee. The study respected the Declaration of Helsinki.

In the beginning 80 consecutive subjects were included in the study, but 9 patients were excluded for partial measurement of ABPM. Therefore, only 71 patients were enrolled into the study. In this group 40 subjects were normal-weight (control group) and 31 patients were obese. 


\section{Anthropometric measurement}

A trained doctor performed the anthropometric measurements. The height was appreciated by using a calibrated scale, for weight evaluations a calibrated electronic weighing scale was used. Body mass index (BMI) was evaluated using the well-known formula: the weight in kilograms divided to the height in square meters $\left(\mathrm{kg} / \mathrm{m}^{2}\right)$. Subjects were classified in the study groups according to BMI criteria.

A BMI higher or equal to the 95th percentile for age and sex defined obesity [9].

\section{Ambulatory blood pressure measurements (ABPM)}

All patients underwent 24-h ambulatory blood pressure monitoring using a validated device (ABPM-05 MeditechKft. Budapest, Hungary). We used appropriate cuff size according to the arm circumference. The non-dominant arm served for cuff placing. The device was set to record BP every 15 min during daytime (from 06:00 to 22:00), and every $30 \mathrm{~min}$ during night-time (from 22:00 to $06: 00)$. Monitoring was performed during an ordinary school day. Subjects were taught not to move and to keep their arm extended and relaxed during each measurement. Patients have been encouraged to do the daily routine activity and they were advised to avoid vigorous physical activity and excess movement within this period.

All ABPM charts were evaluated and we excluded from study those with less than $75 \%$ successfully measurements, those with missing data at more than 3 consecutive measurement, those who didn't respect the day or night-time program or those who removed the recorder.

All patients had diaries and they were asked to note any event, symptom or complaint.

A non-dipping model was considered as a smaller of $10 \%$ reduction in systolic and/or diastolic BP throughout night-time as compared with day-timemeasurements.

The diagnosis of high blood pressure was based on accepted criteria for ABPM. Ambulatory high blood pressure was considered as mean 24-h systolic and/or diastolic blood pressure $\geq 95$ th percentile $[19,20]$. In order to stage correctly the ambulatory BP levels in children we used the Suggested Revised Schema by Flynn et al [14].

Arterial stiffness represents an important predictor of cardiovascular disease. Arterial stiffness increases with age and body weight. Also, it is increased in some pathological conditions: arterial hypertension, diabetes mellitus, hypercholesterolemia and renal failure. Anyway these disorders are themselves associated with increased cardiovascular risk. Arterial stiffness may be assessed using different techniques.

The regression slope of diastolic to systolic BP for each subject, established on the results of the 24-h ABP measurements, was used to obtain the AASI. AASI was computed using the following formula: 1 minus the suitable regression slope. Daytime and nighttime AASI was calculated from the results of awake and asleep ABP measurements.

\section{Statistical analyses}

Data analysis was carried out using the GraphPad Prism 3 statistical package. All values were expressed as mean \pm standard error of the mean. Frequency distributions were used for qualitative variables. Correlations between variables were analyzed by calculating the Pearson's correlation test for data representing Gaussian distribution and MannWhitney test when data were not normally distributed. A statistical significance level was set at a p value of $<0.05$ on two tailed tests.

\section{Results}

Clinical aspects of study group participants are summarized in table I.

All the participants were of Caucasian origin. From71 patients (mean age, $12.58 \pm 3.45$ years; male/female ratio, 1.44),31 (43.66\%) were obesechildren and adolescents.

Mean ages were similar in each group. Both groups included more males than females.

The main anthropometric characteristics of the studied participants were: age, $12.58 \pm 3.45$ years; height, $148.79 \pm 17.51 \mathrm{~cm}$; weight, $54.06 \pm 21.18 \mathrm{~kg}$; body mass index (BMI), $23.68 \pm 6.56 \mathrm{~kg} / \mathrm{m}^{2} ; 59.12 \%$ of the studied group were boys.

As we supposed the obese children were significantly heavier than control subject $(\mathrm{p}<0.001)$, and their mean BMI was considerable higher for age and gender $(\mathrm{p}<0.01)$.

As we expected obese children had significantly higher levels of total cholesterol compared to controls children $(\mathrm{p}=0.0009)$.

The results of 24- hours ambulatory blood pressure monitoring are presented in Table II.

Mean 24-hour, day-time and night-time SBP was considerably higher in the obese group than in the control group $(\mathrm{p}<0.01$ during the entire period). A higher frequency of high SBP readings ( $\geq 95$ th percentile for age and height) was seen in obese compared to controls for the whole period.

In the obese group $45,16 \%$ of the patients were nondippers while in the control group only $5 \%$ of the subjects presented this phenomenon, this difference being statistically significant $(\mathrm{p}<0.0001$; Relative risk $=0.5772$, CI: 0.4161 to 0.8008 ), as shown in Figure 1 .

Table I. Baseline characteristics of participants enrolled in the study

\begin{tabular}{lccc}
\hline Parameter & Obese $(\mathrm{N}=31)$ & Controls $(\mathrm{N}=40)$ & p value \\
\hline Male- N (\%) & $19(61.29 \%)$ & $23(57.5 \%)$ & $\mathrm{ns}$ \\
Female- N (\%) & $12(38.70 \%)$ & $17(42.5 \%)$ & $\mathrm{ns}$ \\
Age (years) & $11.8 \pm 2.91$ & $13.1 \pm 3.73$ & $\mathrm{~ns}$ \\
Height, cm & $148.4 \pm 29.4$ & $146.2 \pm 18.5$ & $\mathrm{~ns}$ \\
Weight, kg & $68.69 \pm 20.5$ & $42.7 \pm 13.4$ & $<0.001$ \\
BMl, kg/m2 & $29.2 \pm 6.16$ & $19.4 \pm 2.23$ & $<0.001$ \\
Total Cholesterol $(\mathrm{mg} / \mathrm{dl})$ & $187.93 \pm 33.89$ & $167.4 \pm 24.49$ & 0.0009 \\
\hline ns, non significant & & &
\end{tabular}


Table II. ABPM characteristics and indices of ambulatory arterial stiffness (AASI) (mean \pm SD) of study groups

\begin{tabular}{|c|c|c|}
\hline Parameter & Obese & Controls \\
\hline \multicolumn{3}{|l|}{$\mathrm{SBP}(\mathrm{mmHg})$} \\
\hline Mean (24-h) & $120.8 \pm 8.35$ & $111.42 \pm 8.61^{* *}$ \\
\hline Day & $125.61 \pm 8.79$ & $115.85 \pm 8.28^{* *}$ \\
\hline Night & $112.67 \pm 8.91$ & $103.65 \pm 9.35^{\star *}$ \\
\hline \multicolumn{3}{|l|}{$\mathrm{DBP}(\mathrm{mmHg})$} \\
\hline Mean (24-h) & $66.06 \pm 7.16$ & $63.65 \pm 5.01$ \\
\hline Day & $70.32 \pm 8.17$ & $67.35 \pm 6.25$ \\
\hline Night & $57.80 \pm 8.24$ & $55.65 \pm 5.18$ \\
\hline 24-h nocturnal SBP reduction (\%) & $10.19 \pm 5.87$ & $12.95 \pm 2.95^{\star \star \star}$ \\
\hline 24-h nocturnal DBP reduction (\%) & $18.03 \pm 9.63$ & $18.52 \pm 6.10$ \\
\hline 24-h heart rate (beats/min) & $82.9 \pm 10.95$ & $81.42 \pm 9.10$ \\
\hline 24-h AASI & $0.45 \pm 0.04$ & $0.41 \pm 0.04^{*}$ \\
\hline Daytime AASI & $0.44 \pm 0.04$ & $0.328 \pm 0.08^{\star *}$ \\
\hline Nighttime AASI & $0.48 \pm 0.05$ & $0.42 \pm 0.08^{\star \star}$ \\
\hline
\end{tabular}

${ }^{*} \mathrm{p}<0.01 ;{ }^{* *} \mathrm{p}<0.001 ;$;** $\mathrm{p}<0.05$

$\mathrm{AASI}$, ambulatory arterial stiffness index; BP, blood pressure

In obese group mean 24-hour SBP was mild correlated with BMI without statistical significance $(r=0.348$; $\mathrm{p}=0.0545)$, while mean 24-hour SBP did not correlate with AASI (r=0.10, p=0.56) (Figure 2).

No correlation was found between 24-hour mean SBP and 24-hour mean DBP respectively with total serum cholesterol $(\mathrm{p}>0.05)$.

Univariate analyses in obese showed that AASI was not related with age $(r=-0.05, \mathrm{p}=0.78)$.

The AASI in normal weight children was lower than in obesechildren.

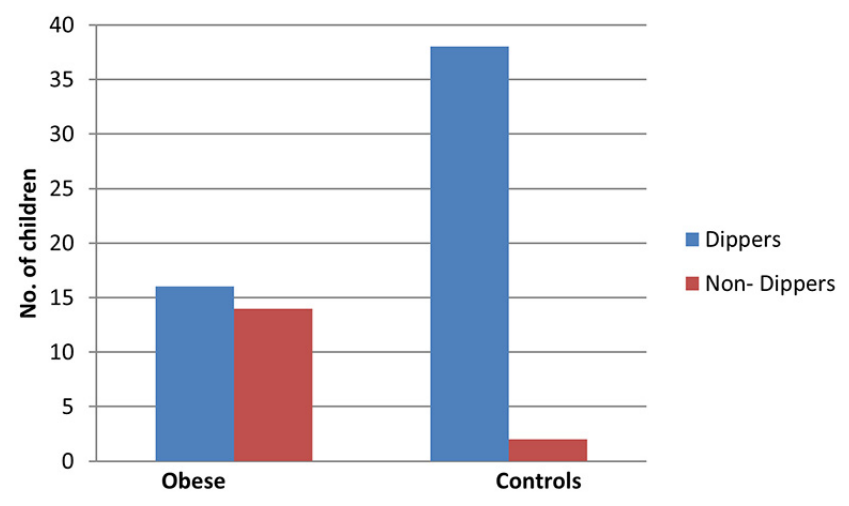

Fig 1. Dippers vs. Non-Dippers in the study groups

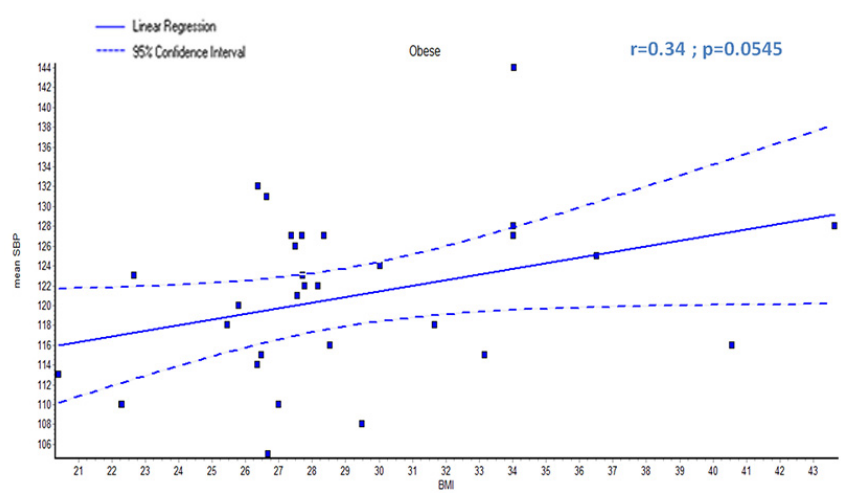

Fig 2. Association between 24-hour SBP and BMI in obese group
The highest values of AASI were observed in obese children during day-time.

Daytime AASI was considerably higher in obese compared to normal-weight children $(\mathrm{p}<0.001)$.

When multivariate analysis was performed, considering AASI as a dependent variable, and all others variable being independent, we found that AASI was dependent on 24-hours SBP, 24-hours DBP $(\mathrm{p}<0.001)$ and on BMI $(p=0.01)$ in obese children.

\section{Discussion}

Because of the important rate of childhood obesity in Romania and worldwide, a special attention is required by the cardiovascular state of children and adolescents.

Body weight fluctuations are accompanied by BP variations. 24-hour ambulatory BP measurements are wide used in children and adolescents. 24-hours BP monitoring is the most precise way to evaluate the BP burden [21]

A positive association between obesity and high blood pressure in children and adolescents was demonstrated by numerous studies [21-23]

The ambulatory BP, especially the systolic BP, was elevated in the obese patients. In our study the diurnal SBP was significantly increased in obese subjects, finding that is in opposition with the results of a recent study where nocturnal BP was increased in obese children and adolescents [21].

The obese group had a significantly higher day-time BP and a relatively/moderately higher night-time BP when compared to the control group. These observations are somewhat similar with those reported by Hvidt [21].

Day-time SBP and night-time SBP were lower in the normal-weight group when compared with the obese group; with similar values to that reported by Hvidt et al in their study [day-time SBP (control: $121 \pm 10.1 \mathrm{~mm} \mathrm{Hg}$; obese: $125 \pm 8.3 \mathrm{~mm} \mathrm{Hg}$; $\mathrm{p}=0.03$ ); night-time SBP (control: $102 \pm 8.2 \mathrm{~mm} \mathrm{Hg}$; obese: $108 \pm 10.7 \mathrm{~mm} \mathrm{Hg} ; \mathrm{p}=0.0001)]$ [7].

Even if obese children had higher values of 24-hours, day-time and night-time DBP than normal-weight children, the difference was not significant. These finding are in part similar with those observed by Hvidt [21]. In discrepancy with our result they observed that night-time DBP (obese: $60 \pm 6.6 \mathrm{~mm} \mathrm{Hg}$; control: $57 \pm 4.8 \mathrm{~mm} \mathrm{Hg}$; $\mathrm{p}=0.001)$ and night-time to day-time BP proportions were higher in the obese group.

In the present research the mean 24-hours, daytime and night-time systolic blood pressure (SBP) in obese children were significantly higher compared to controls, similar to the results obtained by Tekin et al [24].

In their work Tekin et al found that obese children presented significantly higher values of the daytime and 24hour diastolic blood pressure (DBP), results that are discordant with ours.

In the obese children the SBP nocturnal dipping response was less pronounced compared with normal-weight 
children $(\mathrm{p}<0.05)$, these observation being similarly with the result of another study [25]. According to gender the nocturnal dipping for SBP in obese girls did not differ significantly $(\mathrm{p}=0.17)$ (obese $11.91 \pm 4.20$ vs controls 13.9 \pm 3.02$)$ as Framme et al found in their study [25].

In our research the prevalence of nocturnal non-dippers and hypertensive subjects were significantly higher in obese than in normal-weight group. These results are in contradiction with those found in another study where there was no difference between obese and controls [24].

In our obese group, the systolic non-dipping phenomenon was observed in $48.38 \%$, similarly with the frequency reported by Westerstahl [18].

The 24-hours nocturnal SBP reduction was significantly lower in obese subjects compared to controls. This finding is in agreement with the results published by Shikha [23]. For the mean nocturnal DBP reduction the difference was not significant as it was observed in the above mentioned study [23].

The obesity-related elevated day-time and night-time $\mathrm{BP}$ was independent on ambulatory arterial stiffness.

Night-time SBP was not related to AASI as Hvidtobserved in their work, where an association of night-time SBP and arterial stiffness was found [7].

According to $\mathrm{Li} Y$ [16] normal values of AASI are $<0.50$ at 20 years and 0.70 at 80 years.

The nocturnal systolic dip decreased significantly in the obese children compared to controls; finding that is conflicting with the results of Shikha et al [23].

Significantly higher AASI values were noticed in obese children compared to controls (0.45 vs. 0.41, $\mathrm{p}<0.05)$, the difference being more evident for day-time AASI $(p<0.001)$. In their study Saner et al observed a major difference of AASI in obese compared with healthy children $(0.388$ vs. $0.190, \mathrm{p}<0.0001)$. In the same study they didn't remarked any difference between blood pressure values as we did in our research [8].

In the meta-analysis conducted by Kollias et al AASI was correlated with SBP, pulse pressure, and age, contrariwise with the nocturnal SBP and DBP fall [26],results which are in contradiction with our findings.

The results of our research should be apprised in light of some limitations:

the number of participants is relatively small

there are factors unrelated to arterial stiffness which have a strong influence on ASSI (nocturnal BP reduction and the correlation coefficient between DBP and SBP)

This easy-to-use techniqueto appreciate arterial stiffness index in obese children may contribute to their cardiovascular risk stratification.

Hvith et al observed a comparable cardiovascular risk in obese children who became normal-weight before adulthood as those subjects who were never obese $[5,21]$.

Therefore, to prevent irreversible damage of the cardiovascular system, aprompttreatment and prevention of childhood obesity is essential.
In the attempt to decrease exposure to long-time high blood pressure and the upcoming risk of cardiovascular disease, early actions are compulsory needed to reduce childhood obesity rate.

\section{Conclusion:}

This research demonstrates/confirms that SBP and AASI are increased in obese children. AASI is a valuableindex of arterial stiffness that can be simplycalculated under ambulatory conditions in children.

This suggests that obese children may be at an increased risk for developing cardiovascular complications later on adulthood.

\section{Acknowledgments}

This paper was published under the frame of $\mathrm{Eu}-$ ropean Social Found, Human Resources Development Operational Programme 2007-2013, project no. POSDRU/159/1.5/S/136893

\section{Conflict of interest}

The authors declare no conflict of interest.

\section{References:}

1. Valean C. Prevalence of obesity and overweight among school children in ClujNapoca. ActaEndocrinologica (Buc). 2009;5(2):213-219.

2. Emandi A. Chirita, Puiu M, Gafencu M, Pienar C. "Growth references for school aged children in western Romania,"ActaEndocrinologica, 2012:vol.8,no.1,pp.133-152.

3. Mocanu V. Prevalence of Overweight and Obesity in Urban Elementary School Children in Northeastern Romania: Its Relationship with Socioeconomic Status and Associated Dietary and Lifestyle Factors. BioMed Research International 1/2013.

4. Han JC, Lawlor DA, Kimm SY. Childhood obesity. Lancet. May 15 2010; 375(9727): $1737-1748$.

5. Bekkers MBM, Brunekreef B, Koppelman GH, et al. BMl and Waist Circumference; Cross-Sectional and Prospective Associations with Blood Pressure and Cholesterol in 12-Year-Olds. PLoS One. 2012;7(12): e51801.doi:10.1371/journal.pone.0051801.

6. SulákováT1, Janda J, Cerná J, JanštováV, Feber J. Assessment of arterial stiffness from ambulatory blood pressure monitoring in children with diabetes mellitus type-1 (DMT1). J Hum Hypertens. 2012;26(6):357-64. doi:10.1038/jhh.2011.38.Epub 2011 May 5.

7. Hvidt KN, Olsen MH, Holm JC, Ibsen H. Obese children and adolescents have elevated nighttime blood pressure independent of insulin resistance and arterial stiffness. Am J Hypertens. 2014;27(11):1408-15. doi: 10.1093/ajh/hpu055.Epub 2014 Apr 9.

8. Saner C, Simonetti GD, Wühl E, Mullis PE, Janner M. Increased ambulatory arterial stiffness index in obese children. Atherosclerosis. 2015;238(2):185-9.doi:10.1016/j.atherosclerosis.2014. 12.009. Epub 2014 Dec 9.

9. Cole TJ1, Bellizzi MC, Flegal KM, Dietz WH. Establishing a standard definition for child overweight and obesity worldwide: international survey. BMJ. 2000;6;320(7244):1240-3.

10. Falkner Bonita. Recent Clinical and Translational Advances in Pediatric Hypertension. Hypertension. 2015;65:926-931

11. Flynn JT, Daniels SR, Hayman LL, et al. American Heart Association Atherosclerosis, Hypertension and Obesity in Youth Committee of the Council on Cardiovascular Disease in the Young. Update: ambulatory blood pressure monitoring in children and adolescents: a scientific statement from the American Heart Association. Hypertension. 2014;63:1116-1135.doi: 10.1161/HYP.0000000000000007

12. Wühl E, Witte K, Soergel M, Mehls O, Schaefer F; German Working Group on Pediatric Hypertension. Distribution of 24-h ambulatory blood pressure in children: normalized reference values and role of body dimensions [published correction appears in $\mathrm{J}$ Hypertens. 2003;21:2205-2206]. J Hypertens. 2002;20:1995-2007. 
13. Whincup $\mathrm{PH}$, Gilg JA, Donald $\mathrm{AE}$, et al. Arterial distensibility in adolescents: the influence of adiposity, the metabolic syndrome, and classic risk factors. Circulation. 2005;112:1789-1797.

14. Litwin M, Niemirska A, Sladowska J, et al. Left ventricular hypertrophy and arterial wall thickening in children with essential hypertension PediatrNephrol. 2006;21:811-819

15. StergiouGS, Kollias A, Giovas PP, Papagiannis J, Roussias LG. Ambulatory arterial stiffness index, pulse pressure and pulse wave velocity in children and adolescents. Hypertension Research. 2010;33:12721277; doi:10.1038/hr.2010.178

16. Li Y, Wang JG, Dolan E, et al:: Ambulatory arterial stiffness index derived from 24-hour ambulatory blood pressure monitoring. Hypertension. 2006, 47:359-364.

17. Dolan E, Li Y, Thijs L, et al. Ambulatory arterial stiffness index: rationale and methodology. Blood Press Monit. 2006;11(2):103-5.

18. Westerstahl M, Marcus C. Association between nocturnal blood pressure dipping and insulin metabolism in obese adolescents. Int J Obes (Lond). 2010;34(3):472-7.doi: 10.1038/ijo.2009.181. Epub 2009 Sep 15.

19. Lurbe E, Cifkova R, Cruickshank JK, et al. Management of high blood pressure in children and adolescents: recommendations of the European Society of Hypertension. J Hypertens 2009;27:1719-1742.

20. Urbina E, Alpert B, Flynn J, et al. American Heart Association Atherosclerosis Hypertension Obesity in Youth Committee. Ambulatory blood pressure monitoring in children and adolescents: recommendations for standard assessment: a scientific statement from the American Heart Association Atherosclerosis, Hypertension, and Obesity in Youth Committee of the council on cardiovascular disease in the young and the council for high blood pressure research. Hypertension 2008;52:433-451

21. Hvidt KN. Blood pressure and arterial stiffness in obese children and adolescents. Dan Med J. 2015;61(3).pii: B5043.

22. Shi $Y$, de Groh M, Morrison H. Increasing blood pressure and its associated factors in Canadian children and adolescents from Canadian Health Measures Survey. BMC Public Health. 2012;12:388.

23. Shikha D, Singla M, Walia R, et al. Ambulatory Blood Pressure Monitoring in Lean, Obese and Diabetic Children and Adolescents. Cardiorena Med 2015;5:183-190

24. Tekin N, Ersoy B, Coskun S, Tekin G, Polat M. Ambulatory blood pressure parameters in office normotensive obese and non-obese children: relationship with insulin resistance and atherosclerotic markers. Med PrincPract. 2014;23(2):154-9.doi:10.1159/000356120. Epub 2013 Nov 12.

25. Framme J, Dangardt F, Marild S, et al. 24-h Systolic blood pressure and heart rate recordings in lean and obese adolescents. ClinPhysiolFunct Imaging. 2006;26(4):235-9.

26. Kollias A, Stergiou GS, Dolan E, O'Brien E. Ambulatory arterial stiffness index: a systematic review and meta-analysis. Atherosclerosis. 2012;224(2):291-301doi:10.1016/j.atherosclerosis. 2012.03.039. Epub 2012 May 8. 